\section{TRES TIPOS DE COMERCIO TRES MANERAS DE INFLUENCIAR LA ESFERA PÚBLICA DE LOS BARRIOS ${ }^{1}$}

Elke Elisabeth Schlack Fuhrmann², Nancy Rocío Hidalgo Cepeda ${ }^{3}$, Karin Villarroel ${ }^{4}$, María Jesús Arce $^{5}$ y Carolina Fariña ${ }^{6}$.

\section{Resumen}

Considerando que en la teoría urbana el mercado y los espacios públicos están históricamente vinculados, este artículo analiza un mercado, una galería comercial y un centro comercial (mall). El fin es ilustrar los factores que son determinantes para que en Santiago de Chile estas tipologías de comercio adquieran carácter público y puedan contribuir a la esfera pública de la ciudad, al menos dentro de las limitaciones que se derivan de su condición privada. Hasta ahora el debate ha reflexionado extensivamente sobre estas tres tipologías, sin embargo, existen aún pocos estudios que miran la vida pública que tiene lugar en

\section{THREE TYPES OF SHOPPING PRECINCTS THREE DIFFERENT WAYS TO INFLUENCE THE PUBLIC SPHERE OF NEIGHBORHOODS ${ }^{1}$}

Elke Elisabeth Schlack Fuhrmann ${ }^{2}$, Nancy Rocío Hidalgo Cepeda ${ }^{3}$, Karin Villarroel ${ }^{4}$, Maria Jesus Arce $^{5} \&$ Carolina Fariña ${ }^{6}$.

\section{Abstract}

According to urban theory, commerce and public spaces are historically related to each other. Based on this premise, this paper analyzes a market, a shopping center and a mall. The goal of this research is to identify the key factors that turn these shopping precincts into public spaces and contribute to the public sphere in Santiago, Chile, at least within the context of the limitations associated with their private nature. To date, these three typologies have been the focus of intense debate. However, there are few studies of the public life that takes place in these spaces, 
estas diferentes tipologías de manera paralela, considerando que hoy todas ellas están presentes simultáneamente en la ciudad y se disputan su espacio en ella. Esta investigación describe características físicoespaciales y de administración de estos tres casos para aportar a las políticas públicas y el diseño urbano. Se estudia el comercio en relación a la accesibilidad a nivel metropolitano y en cuanto a los diferentes tipos de comercio, que pretenden atraer un público diverso y promueven el carácter público de los espacios.

PALABRAS CLAVE: ESPACIO PÚBLICO, COMERCIO, MALL, GALERÍA COMERCIAL, MERCADO.

Recibido: 30-04-2016

Aceptado: 11-12-2017

1 Este artículo corresponde a los resultados generales de la investigación titulada "Lo público y lo privado en espacios urbanos vitales", proyecto Fondecyt 1120823 realizado entre 2012-2015 y contó con la colaboración de María Elena Ducci, Neil Turnbull, Cristhian Figueroa, Carolina Ramírez y Camila Malig además de los autores del artículo.

2 Chile. Profesora asistente Escuela de Arquitectura, Pontificia Universidad Católica de Chile y Profesora asistente, Escuela de Arquitectura, Campus Creativo, Universidad Andrés Bello. Correo electrónico: eschlack@uc.cl.

3 Chile. Pontificia Universidad Católica de Chile. Correo electrónico: rociohidalgo@uc.cl.

4 Chile. Pontificia Universidad Católica de Chile. Correo electrónico: karinvillarroel@gmail.com.

5 Chile. Pontificia Universidad Católica de Chile. Correo electrónico:mjarce@uc.cl.

6 Chile. Pontificia Universidad Católica de Chile. Correo electrónico: cbfarina@uc.cl. especially when considering that they coexist simultaneously in the city, claiming a space within it. This research describes the physical-spatial and administrative characteristics of these three cases in order to contribute to the strengthening of public policies in urban design. Likewise, commerce is studied in relation to accessibility patterns at metropolitan level and the types of markets that aim to attract different users and promote the public nature of these spaces.

\section{KEYWORDS: PUBLIC SPACE, COMMERCE, MALL, SHOPPING CENTER, MARKET.}

Received: 30-04-2016

Accepted: 11-12-2017

1 This paper presents the general results of FONDECYT Research Project No. 1120823 entitled "Public and Private Spheres in Vital Urban Spaces", conducted from 2012 to 2015 in cooperation with María Elena Ducci, Neil Turnbull, Cristhian Figueroa, Carolina Ramirez and Camila Malig.

2 Chile. Assistant Professor, School of Architecture, Pontifical Catholic University of Chile. Assistant Professor, School of Architecture, Creative Campus, Andrés Bello University. Email: eschlack@uc.cl.

3 Chile. Pontifical Catholic University of Chile. Email: rociohidalgo@uc.cl.

4 Chile. Pontifical Catholic University of Chile. Email: karinvillarroel@gmail.com.

$5 \quad$ Chile. Pontifical Catholic University of Chile. Email: mjarce@ uc.cl.

$6 \quad$ Chile. Pontifical Catholic University of Chile. Email: cbfarina@ uc.cl. 


\section{Introducción}

La literatura reciente acusa la existencia de espacios de consumo que reemplazan el espacio público tradicional. Se argumenta que las cualidades del mercado tradicional de la ciudad europea medieval no están presentes en los espacios de intercambio comercial de las ciudades actuales. Sin embargo, también se han hecho presentes algunas voces que nos recuerdan que fue en el espacio del mercado en el cual se habría desarrollado la forma primigenia de espacio público según Weber (Weber, 1964 citado en Bahrdt, 1979 y Selle, 2003) y que el desarrollo actual del comercio no excluye necesariamente la posibilidad de estos espacios sí contribuyan a la esfera pública de la ciudad. En este artículo reflexionaremos sobre los aspectos socio-espaciales de espacios urbanos dedicados al comercio que promueven la accesibilidad universal y la interacción social y trataremos de responder las preguntas: ¿Podrán un mercado, una galería comercial o un centro comercial aportar a la esfera pública de la ciudad?
¿Qué condiciones debiesen reunir para poder constituirse como espacios de la esfera pública? Si en su origen la actividad de mercadeo en la ciudad europea medieval daba la posibilidad a desarrollar a esfera pública, nos preguntamos, ¿qué faltaría para que hoy, espacios de intercambio comercial metropolitano también cumplan ese rol en la ciudad?

En el entendido de que cada vez más espacios de comercio son creados por iniciativa privada, el trasfondo de esta reflexión es entender los desafíos de los gobiernos locales en la regulación de espacios comerciales en la ciudad, tal como ya se ha discutido en relación a otras ciudades ${ }^{7}$.

Considerando que las 215 hectáreas de superficie que suman mercados, galerías y centros comerciales en Santiago son discretas comparadas con las 3600 hectáreas de áreas verdes públicas de toda la ciudad ${ }^{8}$, creemos que no es la superficie lo que define la magnitud del fenómeno, sino que la presencia y evolución desigual de cada una de estas tres tipologías en la ciudad. Sobre todo, considerando que la literatura tiene una visión crítica del

7 "Plusvalía de localización del espacio público" de Klaus Selle (2003), encargado por el gobierno alemán y “Espacios urbanos en el campo de intersecciones público-privadas", realizada por Berding, Havemann, Pegels y Perenthaler entre 2007 y 2010 con fondos de la Comunidad Científica Alemana (DFG), (Berding, Havemann, Pegels \& Perenthaler, 2010).

8 El valor de las áreas verdes públicas del año 2015 es 35.937 .049 m2. Fuente: Reyes, Pavez, Penas, Salinas, y Hernández, s.f. Ver también: http://www.observatoriourbano.cl/indurb/indicadores.asp accedido el 01-11.2016. 
desarrollo exponencial de Centros Comerciales y de la reconversión creciente de galerías a Grandes Tiendas, las cifras del desarrollo de comercio en Santiago son preocupantes. De las 215 hectáreas dedicadas a comercio establecido en Santiago, un $3 \%$ corresponde a mercados, un $28 \%$ a galerías comerciales y un $70 \%$ a centros comerciales ${ }^{9}$. La evolución de estas tres tipologías de comercio en Santiago es dispareja: desde el 2011 hasta hoy se registra un aumento sostenido de un 40\% de superficies de centros comerciales (Simone, 2017), en cambio, las superficies destinadas a mercados y galerías comerciales se han mantenido o han disminuido.

\section{Marco teórico y objetivo de investigación}

El concepto espacio público se entiende en este artículo como el espacio físico que da cabida a la esfera pública. Mientras el espacio tiene cualidades físicas, la esfera pública está determinada por las interacciones sociales de las personas en el espacio.

9 En este estudio abordamos tipologías de comercio establecido. Las cifras citadas sobre los mercados tienen su fuente en: Arce, 2015. Las cifras citadas sobre las galerías tienen su fuente en: Rosas, 2006; Rosas en llustre Municipalidad de Santiago, 2006; Schlack, 2015. Las cifras citadas sobre los centros comerciales tienen su fuente en Simone, 2017.
De los autores que han abordado el tema del espacio público determinado por su relación con la esfera pública, destacamos a Weber, Bahrdt y Lofland. Lofland concibe las siguientes gradientes entre lo público y lo privado de las interacciones en el espacio: las esferas private (familia), parochial (vecindad), y public (ciudadano) (Lofland, 1998). Bahrdt, basándose en Weber, define la esfera pública como el ámbito social en el que es posible que las personas interactúen entre sí, aunque no se conozcan, con lo cual se genera una red social abierta y define el polo opuesto como la esfera privada donde ocurre la vida entre conocidos y familiares (Bahrdt, 1979).

Wehrheim, quien describe las limitaciones de lo público en los espacios dedicados al comercio, se basa en estos autores y precisa la condición de la esfera pública en los espacios de comercio de la siguiente forma:

Si bien los lugares de comercio son prototípicos del espacio público, porque ofrecen la posibilidad de contacto entre personas que no se conocen, la función del mercado contribuye frecuentemente a legitimar las limitaciones del carácter público de un lugar. Esto ocurre (...) cuando se justifica la exclusión 
de grupos sociales marginales con el argumento de que alteran el clima de consumo, lo que afecta negativamente las posibilidades de darle al espacio usos alternativos (Wehrheim, 2015, p. 297).

Según Wehrheim, también la función política puede ser restringida en un lugar de comercio, lo cual se verifica preguntándose "ise realizan, al menos eventualmente, manifestaciones políticas en el lugar? ¿Se reparten volantes o se colocan puestos de información sobre temas políticos?" (Wehrheim, 2015, p. 297).

Wehrheim concluye acotando que en la ciudad encontramos muchas formas de intercambio comercial que están destinadas a público diferente, configuran lógicas sociales diversas y son distintivas en cuanto a constituir un espacio de funciones sociales, más allá de la función de intercambio comercial (Wehrheim, 2007). Dentro de eso, refiere a lo que podemos esperar de un espacio comercial entendido como un espacio de la esfera pública:

(...) se trata de determinar en qué medida un espacio es un "espacio de posibilidades", que puede ser utilizado y modificado libremente y en el que los presentes pueden estar cumpliendo diferentes roles sociales: paseantes, trotadores, mendigos, activistas políticos, moradores, etc. Esos usos pueden ser igualmente evaluados en relación con las típicas funciones de los espacios públicos, la del mercado y la de la política: iqué negocios hay y que mercadería ofrecen (y con ello, a qué sectores sociales están dirigidos)? (Wehrheim, 2015, p. 297).

\section{El estado del arte de tres tipologías de comercio}

Para ilustrar en qué medida puede existir esfera pública en espacios de comercio, se eligen tres tipologías de comercio contemporáneas que constituyen tipologías arquitectónicas reconocidas en la literatura y de las cuales se ha tematizado su relación con la esfera pública de la ciudad: se trata del mercado, la galería comercial y el centro comercial $^{10}$.

\section{EL MERCADO}

Corresponde a la forma más temprana y de mayor predominio de la vida pública (Weber, 1964; Bahrdt, 1979). Los mercados son organizaciones flexibles en términos espaciales y temporales, que proveen espacios vitales e inclusivos a la ciudad y permiten la improvisada y espontánea sinergia entre personas y comunidades (Janssens \& Sezer, 2013). Estas cualidades constituyen la vitalidad

10 Existe extensa literatura sobre el comercio informal en las calles y en la modalidad de ferias libres. Ha sido abordado sobre todo por Salazar (2003). 
social de la comunidad urbana y la fundación de una democracia funcional (Ünlü-Yücesoy, 2013). En Chile, una de las características esenciales del mercado histórico ha sido el rol activo de los pobres en dar forma a las dinámicas sociales en el espacio público basándose en su cultura de clase trabajadora y popular vinculada a la fiesta popular, tabernas y prostíbulos (Salazar, 2003; Bastías, Hayden, e Ibáñez, 2011). Así, el mercado es un lugar vital para los locatarios formales y los trabajadores informales. Para estos últimos, el mercado no los excluye y es un espacio relevante y apropiado para su forma de vida pública (Márquez, 2014).

Después de la obsolescencia de muchos mercados en los años noventa, en Europa y Norteamérica se inicia un proceso donde los mercados muchas veces serían piezas angulares de la regeneración de zonas urbanas en declive. Esas renovaciones priorizaban el valor simbólico de los mercados como lugares auténticos de actividad social y comercial (Zukin, 1995). En este escenario, se describe cómo los trabajadores y compradores más vulnerables de los mercados están siendo amenazados por la gentrificación y la expulsión de sus barrios (González $\&$ Waley, 2012; Delgadillo, 2017), restando con ello a la diversidad de usuarios y con ello a la calidad del espacio de uso público (Schlack, Turnbull \& Arce, 2017).

\section{GALERÍA COMERCIAL}

Se introdujo en Europa cerca de 1850 como una tipología comercial vinculada a la industrialización y el consumo en masas. Las galerías más antiguas que fueron concebidas como espacios de lujo, sufrieron después procesos de obsolescencia para luego, en tiempos recientes, ser puestas en valor como espacios de alta sofisticación.

En muchas ciudades, las galerías están asociadas a políticas públicas que promueven la cesión al uso público de superficies en el lote privado a cambio de una mayor rentabilidad del suelo (Bannen y Chateau, 2007; Schlack, 2015). Los resultados limitados que han tenido estas políticas públicas en cuanto a que han generado espacios marginales y de poco uso público, hacen dudar de este mecanismo (Von Hagen, 2015; Kayden, The New York City Department of City Planning \& The Municipal Art Society of New York, 2000; Whyte, 1980). Para el caso de Nueva York se describe que los espacios resultantes son desolados y que, a pesar del incentivo que reciben a cambio, los gestores intencionalmente estarían generando espacios que repelen el uso público y es por eso que los espacios se distinguen más por sus cualidades escultóricas y paisajísticas que por su capacidad de acoger la vida pública (Smithsimon, 2008). 
Particularmente en Chile, las galerías han tenido un desarrollo importante en tiempos pasados. Tanto en el centro de la ciudad en los años 1930-1960, como en comunas desarrolladas desde 1970-1980, como es el caso de la comuna de Providencia, donde hay una red considerable de galerías. La literatura sobre las galerías históricas del centro de Santiago se ha centrado en sus cualidades morfológico-espaciales, en las transformaciones que han sufrido en los últimos años por el cierre y reconversión a malls y sobre su aporte a la cualificación espacial y vitalidad del centro de la ciudad (Rosas, 1986; Hermosilla, 2016; Mora y Herrmann, 2016).

Una investigación de las galerías y pasajes que se generaron a través de la planificación por incentivos de Providencia, revisa 62 espacios de uso público en una zona comercial. Esta investigación (Schlack, 2011; Schlack, 2015) confirmó la tesis de que los espacios expresan predominantemente la motivación de sus gestores de construir espacios de vitrinas y comercio. Sin embargo, existen algunas excepciones que logran articular espacios de gran vitalidad. En estos espacios se dan usos públicos, donde es posible la permanencia e intercambio social, una continuidad con la red de espacios públicos del barrio y la presencia de usuarios diversos más allá de los habitantes de los edificios adyacentes (Schlack, 2011; Schlack, 2015).

\section{CENTRO COMERCIAL}

Este ha estado en el centro de la discusión con visiones diversas. Por un lado, se argumenta la sucesiva privatización del espacio urbano (Crawford, 1992; Sato, 1981; Sorkin, 1992; Wehrheim, 2007) y el auge del centro comercial se explicaría a través del deterioro de los espacios públicos tradicionales y una transición en los hábitos del urbanita hacia la vida en espacios de uso colectivo, que son excluyentes para parte de los habitantes (Sorkin, 1992; Wehrheim, 2007). Las reflexiones sobre la esfera pública y el centro comercial se basan en la teoría del miedo al otro, la existencia de una mayor sensación de inseguridad en la ciudad que genera espacios urbanos fortificados, donde solo son bienvenidos los que son "conocidos" o se comportan como tales (Wehrheim, 2007). Los centros comerciales tendrían, debido a las reglas privadas que rigen la vida pública en ellos, un carácter tendencialmente privado (Sorkin, 1992; Crawford, 1992; Frieden \& Sagalyn, 1989; Zukin, 1995). El mall reemplazaría la cultura comunitaria tradicional por una nueva cultura corporativa, donde las personas no puedan sentirse dueñas del lugar (Crawford, 1992; Wehrheim, 2007; Siebel, 2007).

Después de décadas de existencia del centro comercial, se han realizado una serie de estudios 
empíricos, en los que se ha puesto énfasis en la forma que el centro comercial es percibido por sus usuarios. Un estudio muy destacable al respecto es el llevado a cabo por Wehrheim, Siebel y Gestring que muestra cómo las percepciones acerca del centro comercial varían según la experiencia que las personas han tenido a lo largo de su vida con el espacio público (Wehrheim, 2009). Se evidencia que jóvenes que no han tenido la experiencia de vivir en la calle y se sienten inseguros en ella, evalúan el centro comercial como un espacio seguro, confortable y agradable. En cambio, personas de mayor edad que han vivido toda su vida en una estrecha relación con la calle, y se manejan de manera cotidiana con la otredad en la calle, se sienten más cómodos en la calle que en el centro comercial. En Chile, las investigaciones sobre el mall se formulan desde el discurso del espacio público como lugar de expresión de dominio y la apropiación del espacio por jóvenes en el mall, sus percepciones de este como un lugar menos cerrado y menos restrictivo a su forma de vida pública, de lo que se suponía (Simone, 2015; Pérez, Salcedo y Cáceres, 2012; Stillerman, 2006; Stillerman y Salcedo, 2012.

\section{Formas de comercio en la ciudad y su contribución a la esfera pública de los barrios}

El público de los mercados y la forma en que se ha administran han sido los temas fundamentales en la literatura y estudios existentes y el mercado, la galería y el centro comercial han sido mirados predominantemente como tipologías o artefactos aislados. Sin embargo, en la literatura también se ha focalizado la relación entre estas diferentes formas de comercio, sus transformaciones y su yuxtaposición en el espacio de la ciudad. En esa línea encontramos, por un lado, la aproximación de la resiliencia comercial, es decir, la adaptación y reformulación de formas más tradicionales de comercio, sobre todo el comercio informal o el que se basa en comunidades de comerciantes más vulnerables (Erkip, Kizilgun \& Akinci, 2014; Delgadillo, 2017; Duhau y Giglia, 2007). También trata el tema de las edificaciones que estuvieron ligadas a formas de consumo anteriores, la galería comercial, el mercado, que han sido transformados tal como describe Zukin acerca de los así llamados prototipos de la nueva organización del consumo (Zukin, 
1990). Por último, se han realizado algunos estudios comparativos sobre diferentes tipos de comercio enfatizando las prácticas sociales en ellos y su forma de concebir la vida pública (Stillerman, 2006). Así, en la literatura actual se ha descrito cómo antiguas galerías comerciales o mercados son reconvertidos en centros comerciales o calles comerciales se han revitalizado replicando la lógica de las tiendas cadena de un centro comercial en diferentes ciudades del mundo, también en Latinoamérica (Carmona, Magalhaes \& Hammond, 2004; Carmona, 2015; Erkip et al., 2014; Kozak, 2012; Vecslir y Ciccolella, 2011).

La contribución de cada uno de los diferentes tipos de comercio a la esfera pública de la ciudad es un tema aun escaso en el debate. Aún no existe literatura vasta sobre la forma en que mercados, centros comerciales, calles y galerías comerciales, además de comercio ambulante, se disputan espacio en la ciudad. También es difícil trazar paralelos entre las tres tipologías (mercado, galería, mall) bajo el criterio común de sus cualidades de constituir espacio de carácter público y las ventajas comparativas que una $u$ otra tipología puede aportar a las cualidades físico-espaciales de la ciudad. Esta investigación se propone un análisis paralelo de tres tipos de comercio y se pregunta, a través de qué factores, contribuye cada una de estos casos a la construcción del carácter público de Santiago, considerando el contexto espacial y el marco institucional específico de esta ciudad.

\section{Estudio de tres casos en Santiago de Chile}

El desafío metodológico consistió en establecer categorías que permitieran el estudio paralelo de las tres tipologías y de los factores determinantes de su carácter propicio o desventajoso para la construcción de esfera pública. La investigación se basó en la noción de carácter público de Wehrheim, que se refiere a su carácter vinculado a la esfera públi$\mathrm{ca}^{11}$. Según esta noción, el espacio físico del mercado, permite el encuentro entre desconocidos, la relación entre compradores y vendedores en una red social abierta y de accesibilidad universal (Wehrheim, 2009; Selle, 2003 Bahrdt, 1979; Weber, 1964). Este carácter público estudiado se define por consecuente a partir de mucho más que sus meras condiciones físico-espaciales, sino por la interacción entre los usuarios en el lugar y lo que los que administran el lugar promueven.

11 Para la elaboración de la metodología hemos tomado como referencia los estudios de Wehrheim, Gestring y Siebel publicados en Wehrheim en Schlack (2015). 
Se eligieron tres casos que se caracterizan por ser espacios producidos y administrados por privados, por su centralidad urbana y por su gran afluencia de público a través de transporte público ${ }^{12}$. Los tres casos elegidos fueron: el Mercado Vega Central, la galería comercial Plaza Lyon - Paseo Las Palmas y el centro comercial mall Plaza Vespucio.

Esta investigación integró diversas metodologías propias de estudio socio-espaciales ${ }^{13}$ : la observación en terreno mediante fotografías y seguimientos en horarios equivalentemente activos en los tres casos (la Vega cierra antes que los otros casos) y levantamiento planimétrico; encuestas en horarios de actividad equivalente en los tres casos (200 por caso) y entrevistas semi-estructuradas (seis por caso) al público presente en los casos (realizadas en día laboral y día de fin de semana durante los meses de otoño 2013 y primavera 2014 y en horarios equivalentes en los tres casos); entrevistas a los administradores de los casos (tres) y a las autoridades municipales involucradas en los casos. Se definieron los siguientes factores para analizar el carácter público:

- Usos y usuarios: el perfil socio-cultural de los usuarios, su lugar de residencia, cómo llegan al lugar, qué actividades realizan en el lugar y su motivación de la visita.

- La accesibilidad y atracción de flujos: accesibilidad local y metropolitana, integración morfológica y accesos, usos de suelo comercial que atraen flujos de usuarios.

- La administración y gestión del lugar: tipo de administración, usuarios esperados.

Los resultados de estos factores estudiados se integraron en una matriz transversal que permitió describir, qué aspectos de las cualidades físicoespaciales y de la forma de administración podría estar influyendo sobre los usuarios presentes en el lugar y la forma en que estos usan y perciben el lugar.

Las limitaciones metodológicas de esta investigación se desprenden del hecho de haber aplicado una metodología referencial de Alemania, generada en otro contexto cultural y donde la noción de espacio público está configurada de otra forma que en nuestro medio. Sin duda, esto deja fuera reflexiones más profundas sobre la precariedad material del espacio público en nuestro contexto

\footnotetext{
12 Estas categorías fueron definidas por Selle (2003) con el fin de analizar diferentes espacios urbanos que se mueven entre lo público y lo privado.

13 Ver por ejemplo: Sachs, 2002.
} 
FIGURA 1: UBICACIÓN DE LOS TRES CASOS DE ESTUDIO.

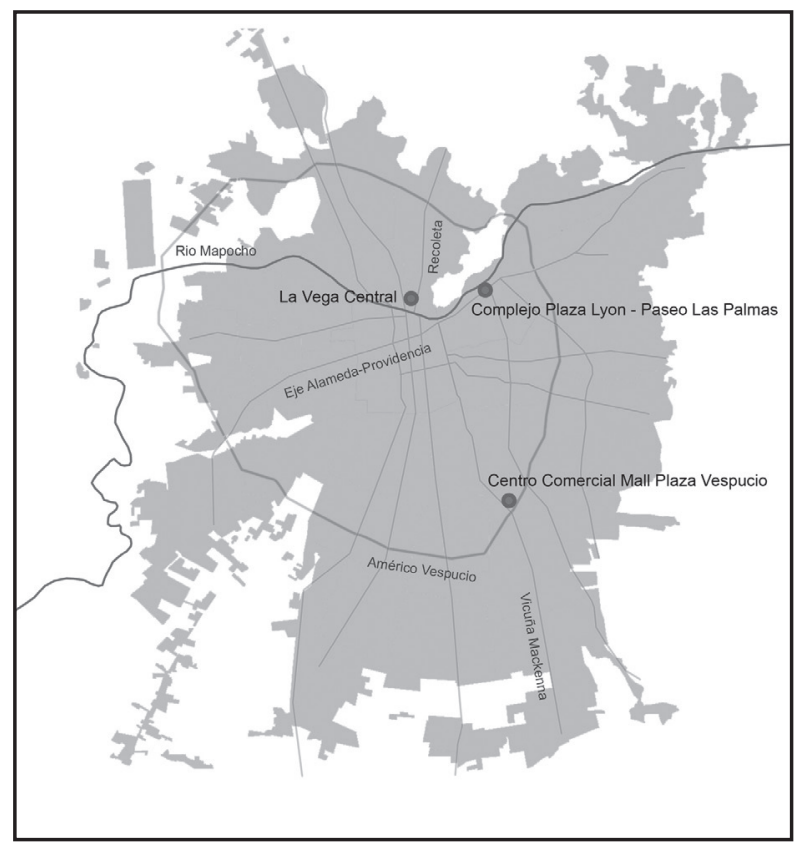

Fuente: C. Figueroa, Proyecto Fondecyt 1120823, 2014. y sobre la posible mayor tolerancia a que el "privado" se haga cargo de brindar espacios de mejor convivencia social y menor riesgo de criminalidad que en el contexto europeo. Otra limitación para generalizar datos a partir de esta investigación se deriva del hecho de que los casos estudiados son ilustrativos y no son esperables las mismas características de todos los mercados, galerías y centros comerciales.

\section{El mercado La Vega Central}

La Vega Central es uno de los principales centros de abastos de alimentos frescos de la ciudad y se ubica en el centro de la ciudad, en una zona de diferentes mercados, bodegajes del comercio mayorista y comercio ambulante. Este lugar se constituyó debido a la presencia de quintas agrícolas donde migrantes del campo comercializaban informalmente sus productos (Bastías et al., 2011, Castillo 2014). La consolidación de la Vega como un mercado formal coincide con un aumento sustantivo de la migración campo-ciudad y la construcción de vivienda social de arriendo en forma de cités y conventillos. 


\section{USOS Y USUARIOS}

En la Vega Central los grupos etarios más representado son tendencialmente de mayor edad que en los otros casos (entre los 30-59 años) ${ }^{14}$ y el objetivo de visita con una mayoría absoluta declarado por ellos es comprar $(93 \%)^{15}$. En comparación a los otros casos, la Vega Central es el que tiene mayor nivel educacional alto y menos diversidad en su composición ${ }^{16}$.

La Vega se describe como un lugar "útil y práctico", debido a la calidad y precio de los productos ${ }^{17}$. Los lugares más visitados corresponden con los de alimentos de primera necesidad y también los lugares

14 En días laborales y festivos la mayoría de los que concurren a la Vega se encuentran entre los 40 y 49 años $(23 \%)$, en segundo lugar están los de 50-59 años (19\%) y en tercer lugar los de 30-39 años $(18 \%)$.

15 Un 17\% de los usuarios de la Vega llegan a pie, en bicicleta o en transporte público o desde comunas más distantes en transporte motorizado (83\%).

16 De los que están presentes en la Vega, $61 \%$ presentan estudios universitarios y $24 \%$ un nivel técnico superior, es decir, un $85 \%$ de la muestra encuestada tiene niveles altos de educación. Los usuarios que finalizaron la educación media constituyen un $11 \%$.

17 Un 19\% de los usuarios de la Vega considera que es un lugar "útil y práctico" (factor relevante en los demás casos también), debido a la calidad, diversidad y precio de los productos. El $16 \%$ de sus usuarios destaca su "buena atención", un aspecto singular de la Vega, y un $13 \%$ de los usuarios consideran que es un "ambiente de gente agradable" (singular en la Vega) y que un valor es "la entretención", que es compartida con los otros dos casos. con productos especiales ${ }^{18}$. También se destaca la cualidad de la "buena atención" y la "entretención". El ser un lugar entretenido tiene que ver con los usuarios presentes en el lugar, los entrevistados valoran la mixtura social y la alegre interacción entre ellos:

Lo que al usuario le gusta del lugar es "La relación personal con las personas, o sea, esa relación que se va gestando en el tiempo, entonces es... yo soy el casero del tipo que me vende (...) y uno se relaciona con las personas, (...) es agradable pasar esa media mañana o media tarde comprando".

En relación al grupo de personas presentes en el lugar, el entrevistado señala:

Bueno, es variopinto, o sea, efectivamente hay gente adinerada, digamos, que viene a La Vega con los mismos principios que yo estoy nombrando y que

18 Dentro de la Vega los lugares más frecuentados que se mencionan son los sectores de alimentos frescos, es decir, verduras y frutas, en segundo lugar, el sector que ofrece productos más específicos, como carne y pescados, alimentos frescos y procesados del extranjero, productos para mascotas, abarrotes, encurtidos, frutos secos, envases, etc. 


\section{FIGURA 2: EL PÚBLICO PRESENTE EN LA VEGA CENTRAL: COMPRADORES Y VENDEDORES.}
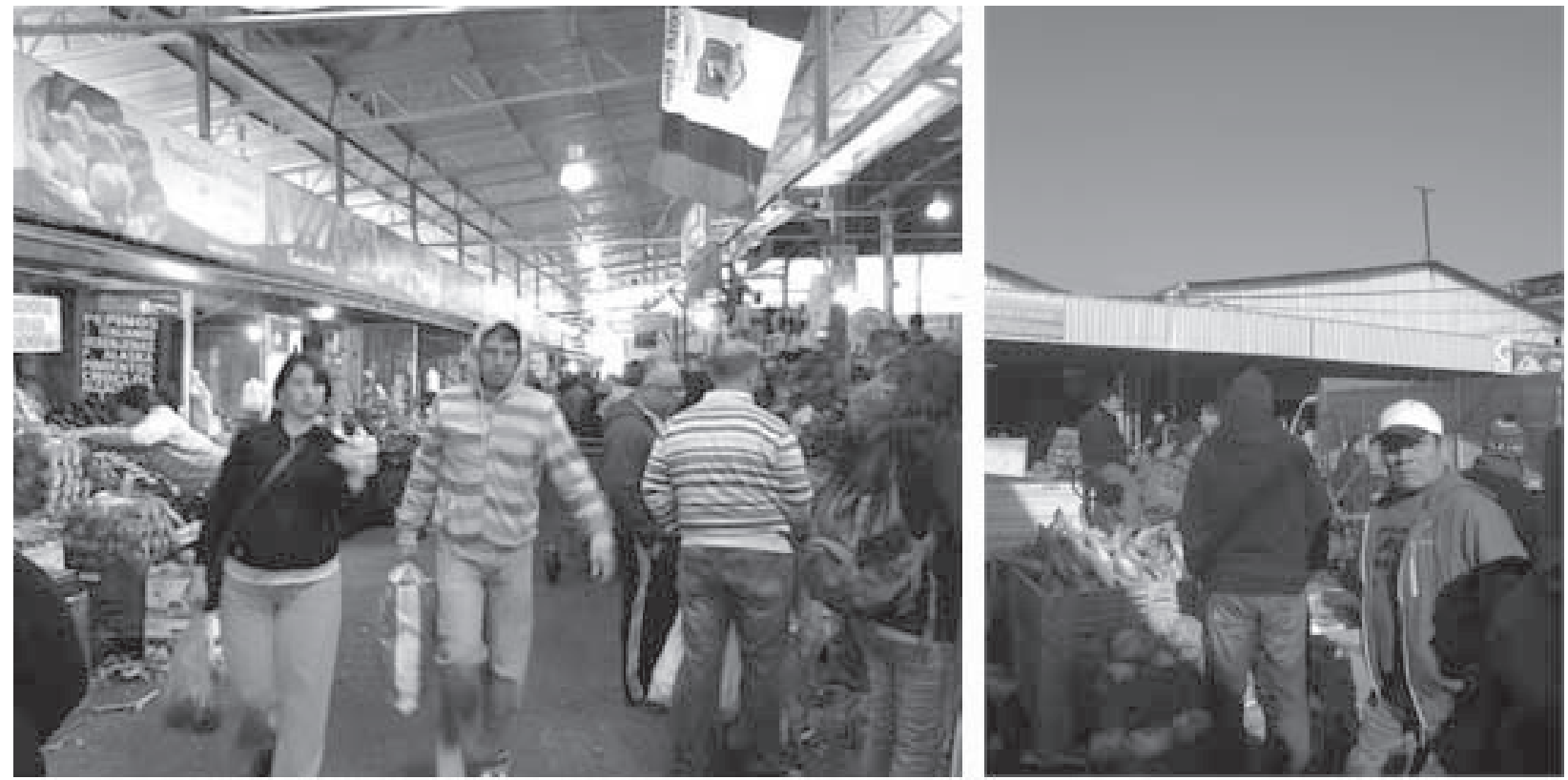

Fuente: autores, equipo proyecto Fondecyt, 2013.

se nota en el estacionamiento, verdad, pagado donde hay coches de lujo, muchas señoras del barrio alto vienen con sus nanas. Pero también uno ve gente de clase, de clases medias y clases medias bajas, digamos, comprando y me gusta que sea, se dé esa relación, verdad, de que sea un punto de reunión donde no hay discriminación, donde la gente se ven como iguales, o sea yo creo que eso es muy positivo de La Vega (Pedro, 61 años, arquitecto).
Los usuarios de la Vega describen también lo característico ligado a la interacción que se da entre compradores y vendedores. Se produce según ellos cercanía, familiaridad con el lugar, una sensación acogedora de ser bien recibidos y bien atendidos. La manera de regatear, ofrecer y vender los productos hace de este lugar un espacio más informal y relajado que resulta entretenido. 


\section{FIGURA 3: LUGAR DE ORIGEN Y DESTINO DEL PÚBLICO QUE VIAJA A LA VEGA CENTRAL. INFORMACIÓN BASADA EN LA GEOREFENCIACIÓN DE LAS 200 ENCUESTAS REALIZADAS.}

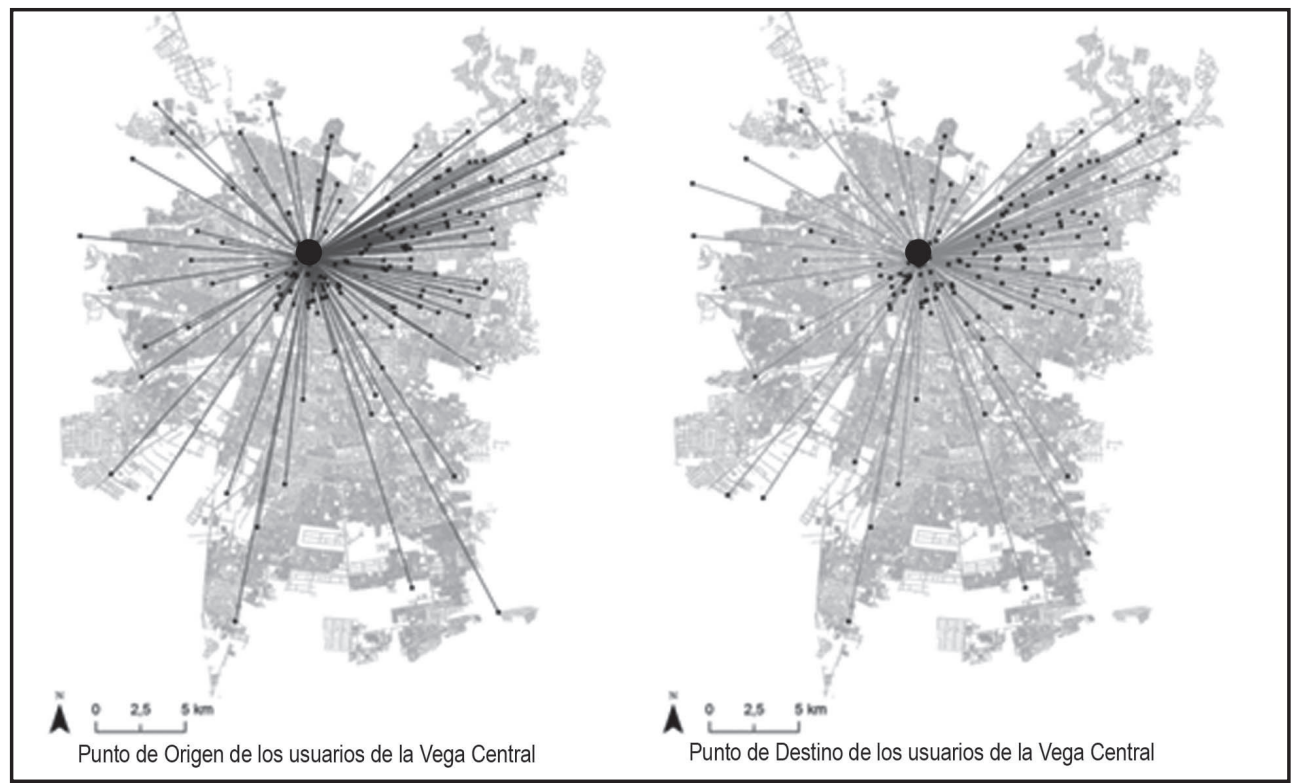

Fuente: Encuestas proyecto Fondecyt 2014; elaboración imagen: Cristhian Figueroa.

\section{LA ACCESIBILIDAD Y ATRACCIÓN DE FLUJOS}

La Vega Central se caracteriza por una ubicación de cercanía peatonal a zonas residenciales centrales y de bajo costo, lo cual promueve el acceso público de la clase socio-cultural media que reside en el centro, así como grupos vulnerables e inmigrantes que viven en habitaciones arrendadas en cités o conventillos, bodegas y sitios en declive alrededor de la Vega. Al mismo tiempo, la Vega es de fácil acceso a través de autopistas intercomunales, lo que explica la presencia de grupos sociales de nivel socio-cultural medioalto que acceden desde sus residencias en barrios de alta renta a través de medios motorizados privados. 
FIGURA 4: CONTINUIDAD PEATONAL CON EL ENTORNO CERCANO Y ACCESOS DEL MERCADO VEGA CENTRAL.

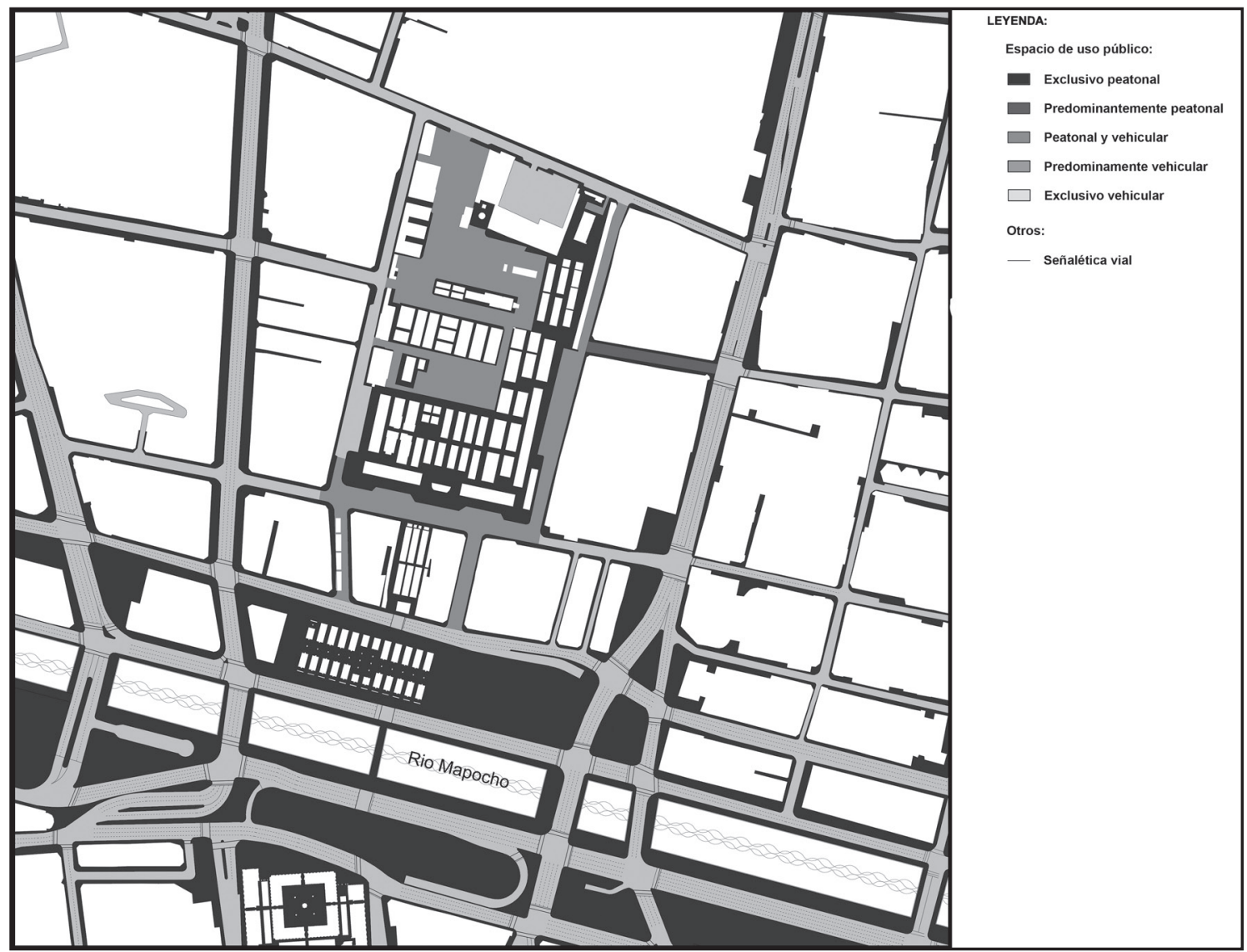

Fuente: Cristhian Figueroa en base a material elaborado por autores investigación Fondecyt, 2014. 
La continuidad espacial con el entorno mediato se debe a la red peatonal de pasajes peatonales y patios al interior de la Vega Central, que se conecta con calles y pasajes del entorno. A pesar de los pasillos laberínticos, el mal estado de los pavimentos y de las medidas estrechas de los espacios de la Vega, la forma en que se ordenan los locales en torno a grandes espacios abiertos y la cantidad de accesos que tiene el lugar, permiten que esta manzana tenga un tejido poroso y permeable a pesar del gran tamaño predial que podría considerarse un obstáculo a la permeabilidad con el entorno. Los accesos son en la mayoría de los casos aperturas libres que solo se cierran en la tarde y noche.

El levantamiento de los tipos de comercio en la Vega Central muestra que gran parte del terreno se ocupa para carga y descarga de productos y su venta al por mayor y menor. Un espacio menor está dedicado a cocinerías y pequeños restaurantes. Los tipos de productos que se comercializan son de primera necesidad ${ }^{19}$ y también productos alimenticios especiales, importados o accesorios a

19 En el sector Chacareros se comercializan productos como frutas y verduras frescas y productos habituales en el comercio de barrio. la alimentación ${ }^{20}$. La diversidad de productos ofertados puede contribuir a atraer a una diversidad de usuarios al lugar.

\section{LA ADMINISTRACIÓN Y GESTIÓN DEL LUGAR}

En 1895 se crea la Asociación de Comerciantes de la Vega Central como una iniciativa privada. En 1930 se traspasa la propiedad al Municipio de Santiago, convirtiéndose en el centro abastecedor mayorista y minorista de productos agrícolas más importante de la capital (Bastías et al., 2011). La forma de tenencia y actual forma de administración de la Vega se origina en 1980, cuando la Municipalidad de Santiago privatiza este mercado municipal, gestionando la venta del predio, producto de lo cual el predio original queda fraccionado en casi mil propiedades individuales asignadas a los diferentes locatarios.

La comunidad de casi ochocientos locatarios y dueños se organiza para definir la organización de los espacios ${ }^{21}$, así como los precios, el tipo de productos y el tipo de vendedores y trabajadores que son admitidos en el lugar. Los veguinos se presentan a sí mismos como una comunidad

20 En el sector remodelado inmigrantes de Perú, Bolivia, Haití y otros países venden productos en el marco de nuevos emprendimientos comerciales: como frutas y verduras de su país, alimentos procesados, quesos y jamones importados correspondientes a nichos más sofisticados de la alimentación.

21 Los estacionamientos, los pasillos comunes entre los locales, la recolección de basura y el aseo, etc. 
con una tradición de atender al cliente mediante cantos y frases, el regateo y una interacción activa con el cliente. La tradición de venta de los locatarios y su disposición de admitir grupos sociales diversos dice relación con la presencia de compradores más vulnerables, pero también de trabajadores informales que pertenecen a grupos socio-culturales menos instruidos y a inmigrantes que han introducido nuevos productos importados al repertorio de la Vega ${ }^{22}$. Esto es lo que se relaciona con la percepción de una mayor diversidad social y un ambiente de vitalidad en el lugar.

\section{La galería Plaza Lyon - Paseo Las Palmas}

Las galerías Plaza Lyon - Paseo Las Palmas se ubican en una zona inicialmente residencial, que en 1970 sufre una renovación urbana importante, consolidándose como un sub-centro comercial, donde la avenida Providencia es su calle principal y dos estaciones de Metro, que se ubican a cinco

22 La comunidad de la Vega acoge solidariamente a trabajadores vulnerables, mendigos e inmigrantes, reconociéndolos como personas de su mismo origen social y regulando la seguridad y el buen trato de los clientes (Arce, 2015). cuadras, proveen su accesibilidad metropolitana. Una política de incentivos a la densificación existente desde 1976 promovió que se incluyeran galerías en las plantas bajas y subsuelos de los edificios y que se generara una red de pasajes de todos los edificios y de las estaciones de Metro (Bannen y Chateau, 2007; Hidalgo, 2011; Schlack, 2015). El conjunto Plaza Lyon - Paseo Las Palmas se construyó en 1980 en el marco de una colaboración entre municipio y desarrolladores, que promovió que los pasajes apoyaran la calidad peatonal y comercial en esta nueva zona. Si bien los pasajes son parte de la propiedad privada, aquellos que se acogieron a la normativa de incentivos, están obligados a la cesión al tránsito público, por lo que estos pasajes debiesen permanecer abiertos durante las horas hábiles del barrio (Schlack, 2015).

\section{USOS Y USUARIOS}

Los usuarios de las galerías Plaza Lyon - Paseo Las Palmas son mayoritariamente personas jóvenes entre los 20-39 años ${ }^{23}$. Ellos declaran que el objetivo de la visita es más allá de comprar, el hacer una pausa en el paso, consumir y hacer

23 La población predominante se encuentra entre los 20-29 años (29\%). Sin embargo, también son relevantes los usuarios en el tramo etario de $30-39$ años $(24 \%)$ y de $40-49$ años $(20 \%)$. 
trámites ${ }^{24}$. Las galerías muestran mayor diversidad en la composición educacional de su público, de la misma forma que el centro comercial ${ }^{25}$. En la galería lo "útil y práctico" es descrito como su condición más relevante. Además importa a sus usuarios, el ser "entretenido" y "quedar en el camino"26. Los lugares más visitados lo constituyen el Paseo Las Palmas y también otras galerías del entorno que para el usuario parecieran ser parte del conjunto ${ }^{27}$.

Para los visitantes aparece atractivo que los locales son los mismos hace mucho tiempo y que son "atendidos por su dueño". Los usuarios valoran también la diversidad del público presente y

24 El público de las galerías considera que su motivo de visita principal es comprar (29\%), no obstante, también otros fines como el ser parte de un recorrido al trabajo 0 a casa $(20 \%)$, el consumir entretenimiento o gastronomía (16\%) y hacer trámites $(13 \%)$ son importantes en su visita.

25 La mayoría del público de la galería, el $71 \%$, posee un nivel educacional alto: educación universitaria $(46 \%)$ y educación técnica nivel superior (25\%). Entre los demás usuarios predominan los que tienen educación media (18\%).

26 La galería es considerada por un tercio de los usuarios como "útil y práctico" (35\%), una característica predominante también en los otros casos de estudio. Un segundo tercio considera la galería un espacio "entretenido" $(28 \%)$. Los usuarios también destacan, que la galería "queda en el camino" $(13 \%)$ y que es un lugar con "seguridad" (8\%) y un "lugar concurrido" (7\%).

27 Los usuarios de la galería la consideran parte de un conjunto de galerías, que ellos visitan sin hacer distingos. Mencionan como parte de la galería el Centro Comercial ubicado en la manzana aledaña (mall Panorámico), la parte al aire libre de la galería "Paseo Las Palmas" y el centro comercial en la manzana del frente (Portal Lyon) como lugares habituales de destino. la multiplicidad de la oferta comercial ${ }^{28}$ como se describe a continuación:

(...) Vengo al dentista, (...) voy también a supermercado, (...) La verdad es que me atrae porque tiene de todo, cosa que uno busque, lo encuentra, además que tiene donde comer, entonces es bien completo. (...) hay consultorios médicos, hay tiendas, muchas tiendas, los chocolates (...) tomarse un cafecito, ir a una heladería, ese tipo de cosas. (Rosalía, 73 años, jubilada).

28 La galería es atractiva por su variedad de productos, entre los que se destacan los estandarizados (tiendas cadena), los especializados (coleccionismo, videojuegos, comics, sex-shops, etc.) y comercio de barrio (arreglo de relojes, peluquerías, librerías, menaje, suvenires, bazares). Esta diversidad de comercios atrae a una diversidad de compradores: adultos, jóvenes y de la tercera edad, quienes destacan de acuerdo a sus respectivas cualidades la "familiaridad", lo "underground", etc. 


\section{FIGURA 5: ENTRADA A LA GALERÍA COMERCIAL DESDE UNA VEREDA PÚBLICA EN EL CONJUNTO PLAZA LYON - PASEO LAS PALMAS.}

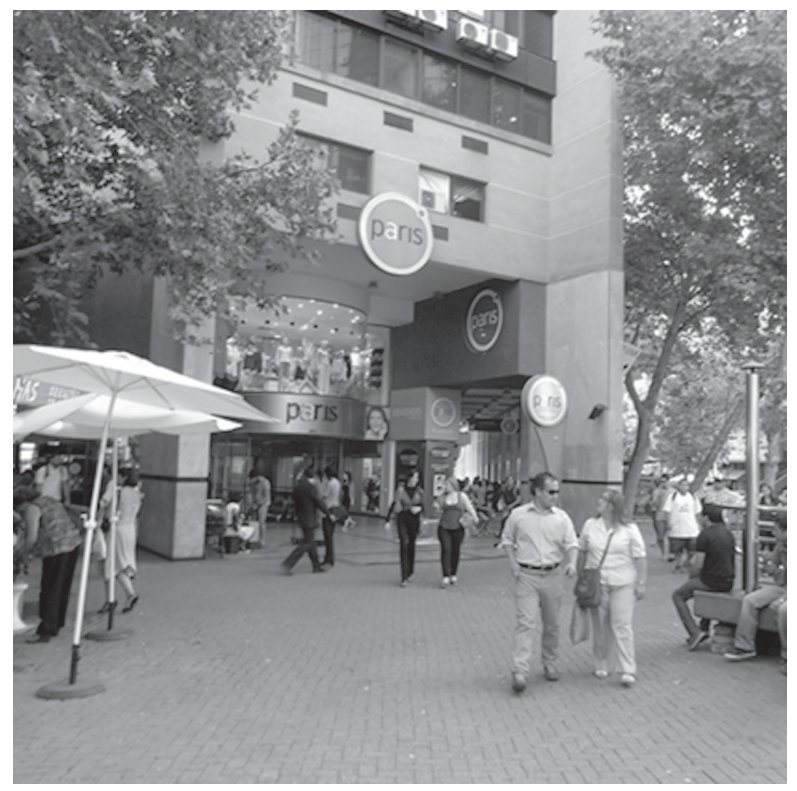

Fuente: autores, equipo proyecto Fondecyt, 2013.

\section{LA ACCESIBILIDAD Y ATRACCIÓN DE FLUJOS}

Las galerías Plaza Lyon - Paseo Las Palmas constituyen una red dentro de los edificios que se conectan entre sí y con las veredas públicas. Las personas presentes en el lugar que viven en barrios cercanos, llegan a pie, bicicleta o en transporte público al lugar. Pero también son accesibles a través del transporte público (bus y metro), desde diversas zonas distantes de la ciudad. La concurrencia de personas de un nivel socio-cultural diverso puede obedecer a esta doble condición de accesibilidad metropolitana y local muy fluida ${ }^{29}$.

La red continua de veredas públicas y galerías comerciales hace que la accesibilidad peatonal de las galerías sea muy expedita. Las galerías se insertan en una manzana de gran porosidad, tienen varios accesos y se articulan con otras galerías de la zona. Además, el lugar se constituye con una mezcla programática en la que combinan comercio, oficinas y vivienda, de la misma forma como ocurre en toda esa zona de Providencia. La galería Paseo Las Palmas se presenta como una calle peatonal techada completamente abierta y los demás accesos de la

29 Las personas que viven en barrios cercanos y tienden a un nivel socio-cultural más alto, llegan a pie 0 en bicicleta a estas galerías. Las personas que viven más distantes, tienden a pertenecer indistintamente a un nivel socio-cultural alto (universitarios), medio (técnicos) y medio bajo (educación media) y acceden al lugar en transporte público y suelen estar de paso en el lugar o trabajan cerca. 
FIGURA 6: LUGAR DE ORIGEN Y DESTINO DEL PÚBLICO QUE VIAJA A LA GALERÍA PLAZA LYON-PASEO LAS PALMAS. INFORMACIÓN BASADA EN LA GEOREFENCIACIÓN DE LAS 200 ENCUESTAS REALIZADAS.

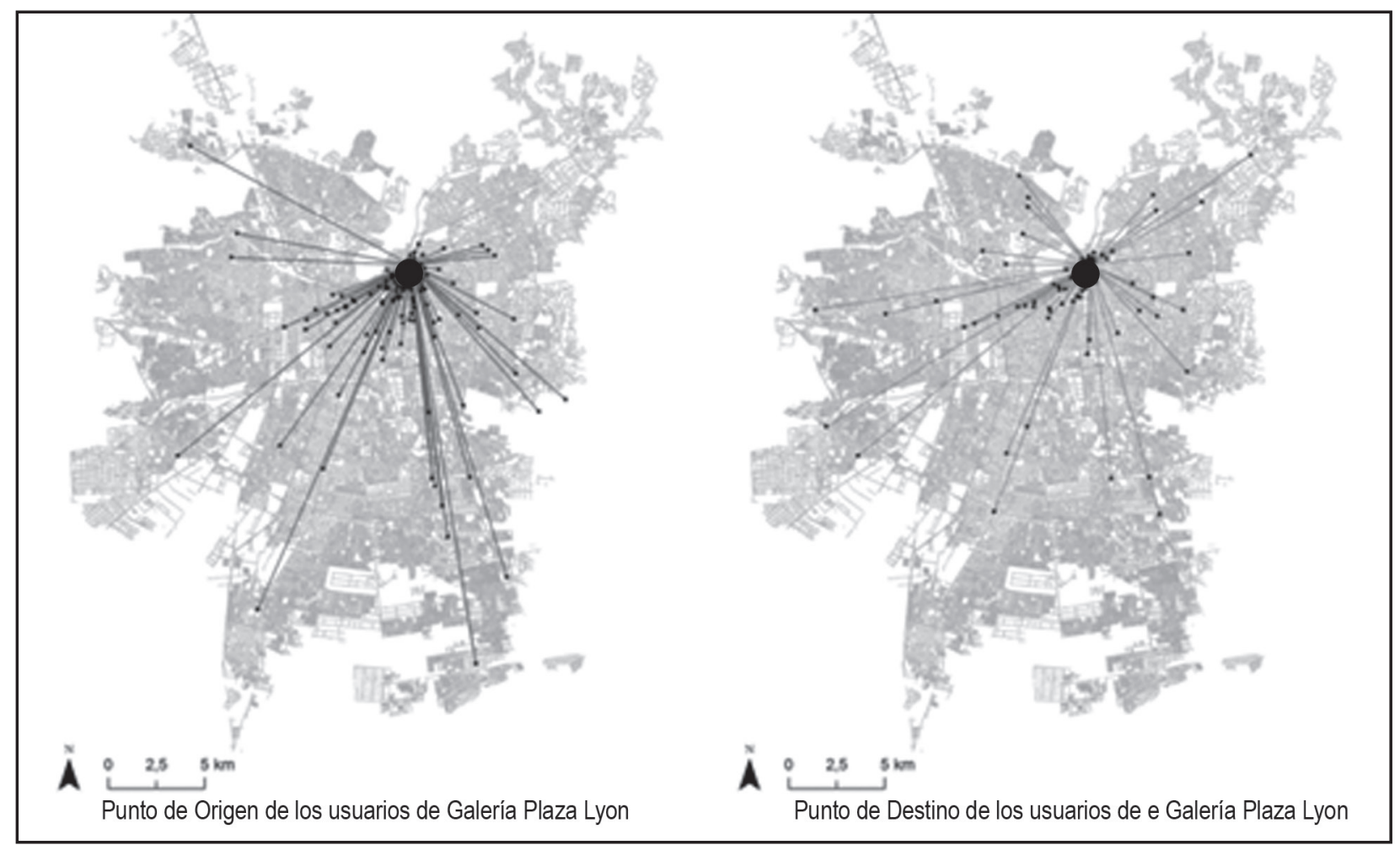

Fuente: Encuestas proyecto Fondecyt 2014, elaboración imagen: Cristhian Figueroa. 
FIGURA 7: CONTINUIDAD PEATONAL CON EL ENTORNO CERCANO DE LA GALERÍA PLAZA LYON Y PASEO LAS PALMAS.

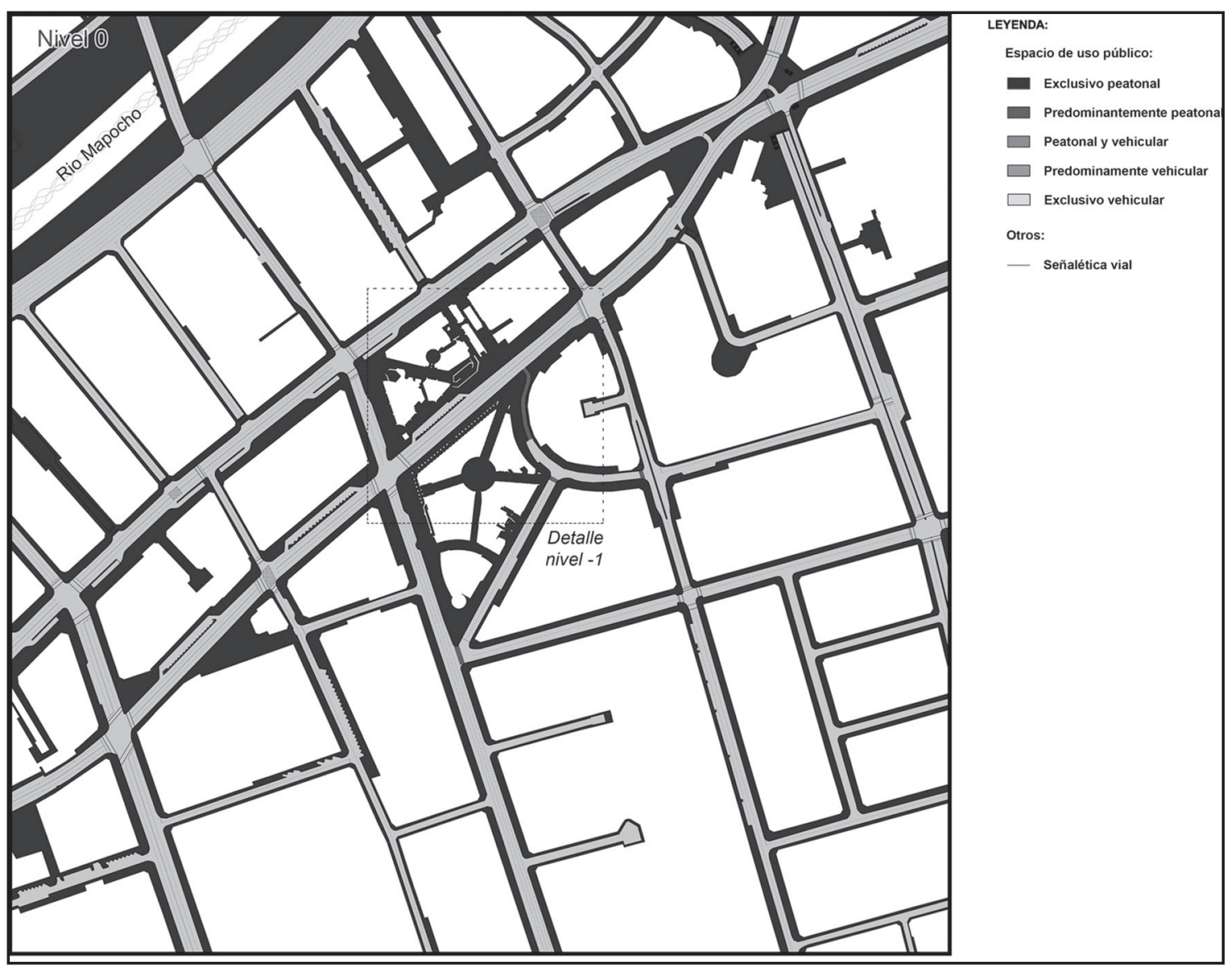

Fuente: Cristhian Figueroa en base a material elaborado por autores investigación Fondecyt, 2014. 
galería Plaza Lyon se constituyen como aperturas libres de portales que solo se cierran en la noche.

El levantamiento de los tipos de comercio de las galerías Plaza Lyon y Paseo Las Palmas muestra diversos tipos de comercio: estandarizado y específico, así como la mixtura existente en el entorno ${ }^{30}$. Además del comercio, el conjunto contiene viviendas y oficinas que activan el lugar fuera de las horas que el comercio está abierto. Es muy probable una incidencia de la variedad y tipo de usuarios que concurre al lugar en términos de edades y también del tipo de consumo, con el tipo de comercio instalado en estas galerías.

\section{LA ADMINISTRACIÓN Y GESTIÓN DEL LUGAR}

La administración de las galerías está en manos de los copropietarios de cada uno de los seis edificios que componen el conjunto. En estos edificios coexisten comercio, oficinas, viviendas. Los intereses de los distintos actores son diversos en relación a la mantención y ambientación de las galerías comerciales. La diversidad de estas galerías está dada por la diversidad de

30 Más del $50 \%$ del comercio consiste en tiendas de cadena internacional y nacional (Almacenes París y Líder) y la otra mitad la constituyen restaurantes al paso, bancos y reparadores de calzado, taller de llaves y comercio de barrio y algunas tiendas de emprendimientos especializados (videojuegos, coleccionismo, etc.). los dueños de locales comerciales ${ }^{31}$. Todos los dueños de los locales comerciales (corporativos y unitarios) guardan tolerancia hacia un público de paso: peatones camino al trabajo, al colegio, al hogar o al paradero de bus o metro. El flujo de público de estas galerías es intenso debido a su accesibilidad directa a la estación de Metro. Esto ha generado una disposición más tolerante de la administración ante la habitual presencia de comercio ambulante, estudiantes ociosos y mendigos, que son admitidos por la administración a ciertas horas y en ciertos lugares limitados de las galerías. En general, la administración del conjunto se encuentra en una controversia interna acerca de implementar una política de "privatización" del espacio libre a través de concesiones a actividades de las grandes tiendas o de abrir al uso público como sucede en los espacios apropiados temporalmente por vendedores ambulantes.

31 La comunidad está conformada por dueños corporativos (tiendas cadena) y por una diversidad de dueños de locales unitarios. 


\section{El centro comercial mall Plaza Vespucio}

El centro comercial mall Plaza Vespucio tiene una morfología que se caracteriza por volúmenes cerrados y extensiones grandes de estacionamiento. El centro comercial se emplaza en el sub-centro de una comuna periférica y se ubica en el cruce de dos autopistas metropolitanas y entre dos estaciones de Metro de acceso desde la periferia de la ciudad. El lugar se había desarrollado con comercio local y servicios públicos de la comuna antes de que el centro comercial se instalara allí. El centro comercial se destaca fuertemente de su entorno tanto por la gama mayor de servicios que ofrece como por la arquitectura corporativa unitaria que representa.

\section{USOS Y USUARIOS}

En el centro comercial el público es muy similar al que observamos en la galería Plaza Lyon y pertenece en su mayoría al grupo etario de entre los 20 y 39 años $^{32}$. La motivación de la visita de estos usuarios es comprar, pero también realizar trámites y consumir gastronomía ${ }^{33}$. El resultado de las encuestas mostró una más homogénea representación de todos los grupos socio-culturales en el centro comercial que en los otros $\operatorname{casos}^{34}$. El centro comercial es "útil y práctico", además de "entretenido" y "seguro" para sus usuarios. A diferencia de los otros dos casos, la seguridad es un factor de atracción ${ }^{35}$. La tienda ancla (Falabella) y el patio de comidas donde se encuentran los restoranes y cafés son los lugares de destino primordiales del centro comercial.
El público del mall Plaza Vespucio corresponde mayoritariamen te al tramo de edad entre los $20-29$ años $(33 \%)$, seguido por el de 30-39 años (24\%) y el de $40-49$ años (13\%).

33 El motivo principal de la visita al centro comercial es comprar $(29 \%)$, realizar trámites $(17 \%)$, consumir entretenimiento o gastronomía $(16 \%)$ y el pasear $(10 \%)$.

34 Así los grupos más representados en el lugar son de educación media $(31 \%)$, de técnico-nivel superior $(26 \%)$ y universitarios $(25 \%)$, y el grupo de personas con educación básica $(7 \%)$ es mucho más alto que en los otros dos casos.

35 El mall es para sus visitantes un lugar "útil y práctico" $(22 \%)$, "entretenido" (22\%), que da "seguridad" $(16 \%)$ y se constituye como un "lugar concurrido" (10\%). 


\section{FIGURA 8: INTERIOR DE MALL PLAZA VESPUCIO.}

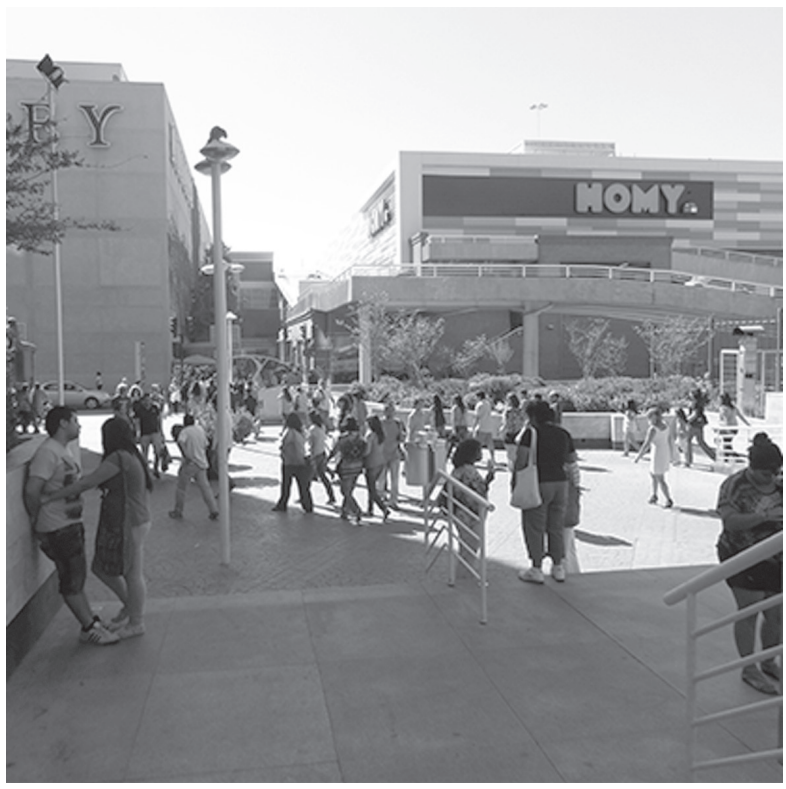

Fuente: autores equipo Fondecyt, 2014.
La variedad de la oferta para ir de compras de primera necesidad (supermercado), en tiendas de vestuario, realizar trámites como pagar cuentas constituyen los mayores atractivos del centro comercial. También la entretención es un factor importante para los visitantes, tanto en el patio de pubs (Las Terrazas) o paseando por los circuitos del mall. Los usuarios perciben con una sensación de inseguridad a visitantes disruptivos del entorno $y$ en el centro comercial ${ }^{36}$.

Una de las motivaciones para visitar el lugar es la diversidad de servicios:

(...) Es que encuentro que ahí está todo, en esa zona ahí es como está todo, hay donde pagar cuentas, ahí puedo pagar teléfono, puedo pagar, es que no sé po, sin fin de cosas, hay... hay hartas cosas, hay icómo se llama esta? Servipag, donde pagar, hay Sencillito, hay... o sea es (ya), hay lugares donde comer (ya...), es como bien completo, entonces ipara qué venir a meterse al centro si tengo ahí mismo lo que voy a buscar? (Teresa, 55 años, trabajadora de casa particular).

36 Según los entrevistados, el mall se distingue por una mayor seguridad que el barrio del entorno. La presencia de personas de un estrato inferior o de grupos de jóvenes disruptivos es mal vista por las familias que recorren este lugar. 
FIGURA 9: LUGAR DE ORIGEN Y DESTINO DEL PÚBLICO QUE VIAJA AL CENTRO COMERCIAL MALL PLAZA VESPUCIO. INFORMACIÓN BASADA EN LA GEOREFENCIACIÓN DE LAS 200 ENCUESTAS REALIZADAS.

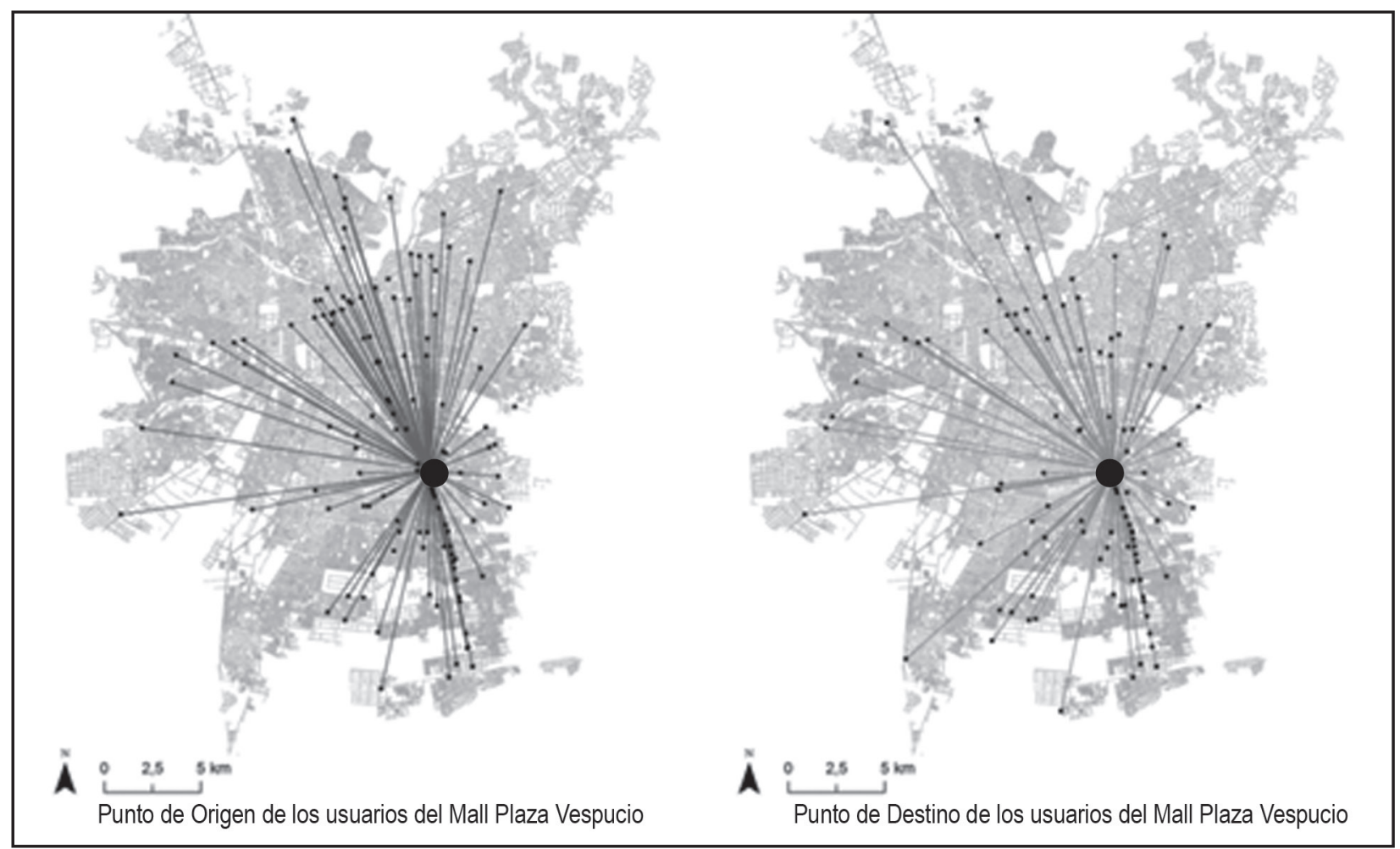

Fuente: encuestas proyecto Fondecyt 2014, elaboración imagen: Cristhian Figueroa. 
FIGURA 10: CONTINUIDAD PEATONAL CON EL ENTORNO CERCANO DEL CENTRO COMERCIAL MALL PLAZA VESPUCIO.

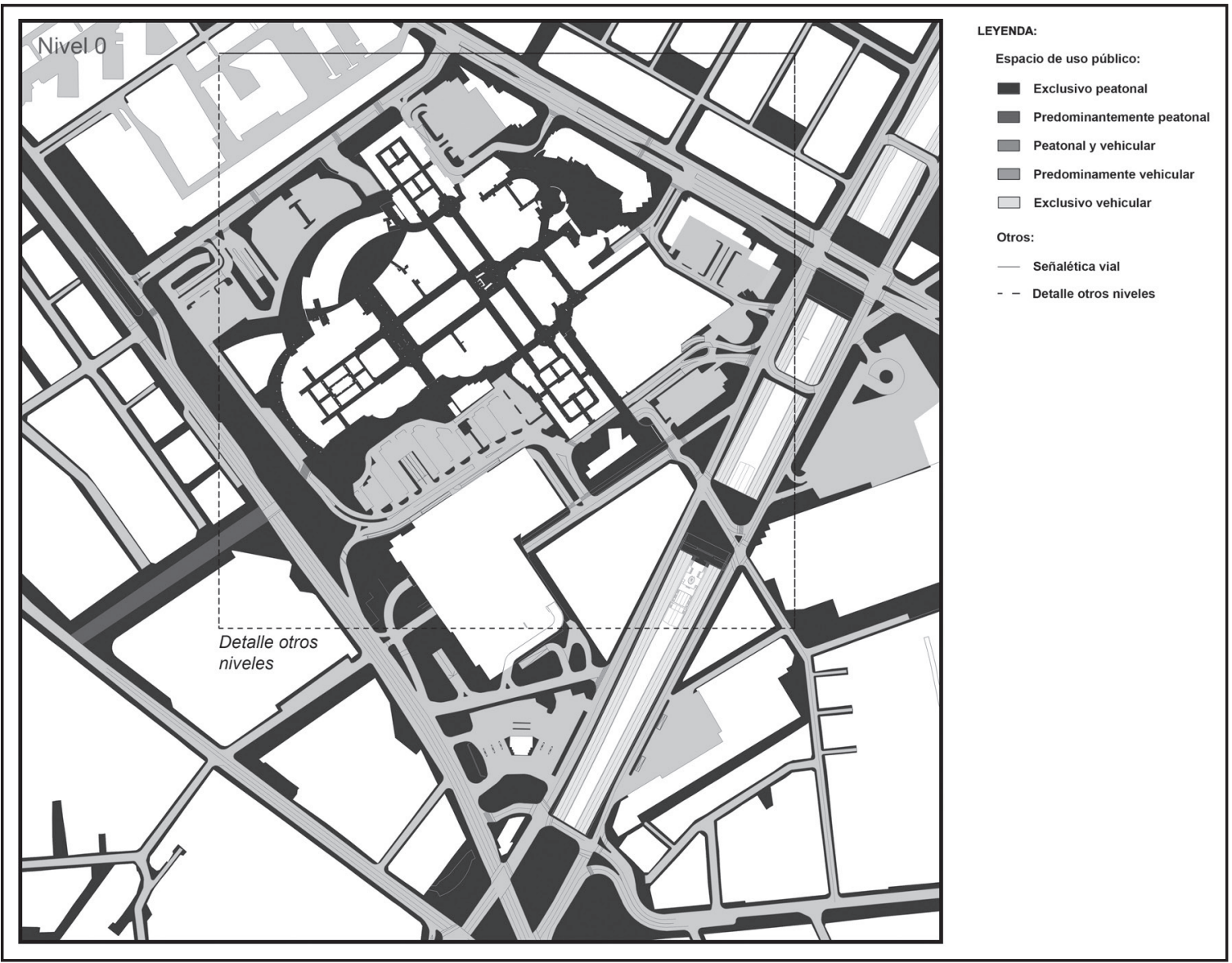

Fuente: Cristhian Figueroa en base a material elaborado por autores investigación Fondecyt, 2014. 


\section{LA ACCESIBILIDAD Y ATRACCIÓN DE FLUJOS}

Dos líneas de metro permiten que el mall Plaza Vespucio tenga una accesibilidad desde comunas muy distantes de la ciudad en un tiempo de viaje aproximado de máximo 45 minutos. La continuidad peatonal hacia el acceso del mall desde las dos estaciones de metro cercanas es muy expedita. La accesibilidad peatonal desde los barrios cercanos es deficiente y cruza un entorno muy hostil por el alto flujo vehicular.

El contexto mediato del centro comercial presenta un tejido urbano fragmentado debido a las autopistas de alta velocidad e infraestructuras de Metro elevadas o en trinchera que lo atraviesan (Villarroel, 2014; Fariña, 2015). El entorno mediato del centro comercial es hostil al peatón y muy discontinuo espacial- y funcionalmente respecto de los espacios internos del centro comercial ${ }^{37}$. Si bien existe una cantidad razonable de accesos, tienen la forma de exclusas controladas, ya sea visibles como accesos vehiculares hacia el entorno o accesos con puertas y control en todos los horarios del día.

La fragmentación de esta zona se debe a un proceso no planificado, donde se fueron sucediendo

37 Ver en detalle el desarrollo de este tema en: Fariña, 2015 y Villarroel, 2014. diversos desarrollos inorgánicamente ${ }^{38}$. La condición de accesibilidad directa desde el transporte público por un lado y fragmentada para los peatones de los barrios aledaños hace que el público proviene predominantemente de lugares lejanos y no del barrio.

Los tipos de comercio del centro comercial constituyen una aglomeración de comercio predominantemente de cadena nacional e internacional que contrasta fuertemente con la mixtura de comercio de barrio y comercio de cadena nacional presente en el entorno del centro comercial. En este caso, la multiplicidad de usuarios no es necesariamente atribuible a una diversidad de comercios, sino más bien a una oferta gastronómica y de entretenimiento (cine), que hace que este lugar se destaque del entorno urbano falto de equipamiento de ese tipo. En relación a los demás casos, en el mall hay una mayor dispersión del nivel socio-cultural de los usuarios. Los visitantes de nivel socio-cultural diverso vienen tanto de lugares distantes (Cerro Navia, Quilicura) como del entorno cercano del mall. Si bien se podría pensar que la dispersión de habitantes se podría deber a la diversidad

38 Tanto la vivienda social construida por el Estado, como la gestión inmobiliaria privada generaron una ocupación de paños agrícolas de forma discontinua (Montes, 1989). El terreno del centro comercial constituía antes un asentamiento informal y hoy es propiedad del holding internacional dedicado al retail mall Plaza S.A. 
social de los barrios del entorno, esto no es así, en ello puede incidir la fuerte discontinuidad física entre el comercio del mall y los barrios del entorno.

\section{LA ADMINISTRACIÓN Y GESTIÓN DEL LUGAR}

El centro comercial mall Plaza Vespucio es administrado por un dueño corporativo, una empresa de retail que es dueña del suelo y del conjunto edificatorio. La administración se encarga de arrendar locales y organizar las actividades en los espacios comunes (pasillos, patios de comida, plazas exteriores, etc.). El administrador corporativo diseña los locales y define los horarios de atención, provee un sistema de seguridad, produce una constante renovación de los espacios comunes y de eventos promocionales para atraer al público. La administración declara estar particularmente interesada en que sus usuarios sean predominantemente familias y ello se condice con el tipo de comercio dispuesto para los usuarios: restoranes, bares familiares, cine. El acceso está prohibido a personas de aspecto amenazador para los visitantes, cómo jóvenes desafiantes, mendigos y vendedores ambulantes y se ejerce un estricto control al respecto. Eso se condice con la percepción que también los usuarios tienen del mall, que quieren sentirse resguardados de usuarios maleducados y amenazantes.

\section{Conclusiones y discusión}

Este artículo presenta tres diferentes tipologías de comercio que hoy conviven en la ciudad y en Santiago de Chile en particular. En el marco de un debate eximio sobre la contribución de espacios urbanos administrados por privados a la esfera pública de la ciudad (Schlack, Hidalgo, Arce, Fariña y Villarroel, 2017; Schlack, 2015), nos interesó ahondar en este tema, considerando que es necesario mayor conocimiento para aportar a la toma de decisiones de municipios y gobiernos locales, que muchas veces están frente a la disyuntiva de elegir entre promover una u otra tipología comercial en la ciudad. Aunque en nuestro medio se defienda cada vez más la idea de la coproducción de espacios urbanos entre instituciones públicas y privadas, no deja de tener prioridad la reflexión sobre regulaciones que ayuden a que incluso el comercio en la ciudad se conciba bajo las lógicas de inclusión social.

En nuestro medio, la preocupación por un apropiado diseño y renovación de galerías, mercados y centros comerciales suele formularse en relación a su aspecto morfológico y funcional. Sin embargo, es discutible el valor socio-espacial de estrategias como la reconversión de antiguas fábricas a centros comerciales, la incorporación de grandes tiendas en una antigua galería comercial o de un mercado o la adición de programas como clínicas, 
canchas de patinaje, lagunas outdoor a los centros comerciales. Cuando se valoran este tipo de intervenciones se da menos importancia a la condición socio-espacial que estos aportan a nuestra vida cotidiana y evaden la pregunta sobre su contribución a la esfera pública.

Este artículo es parte de una discusión aun en curso que se pregunta ien qué medida espacios dedicados al comercio, de por sí, dejan de ser o son espacios pertenecientes a la esfera pública? Por un lado, adherimos a la noción de que el arquetipo del espacio público se ha originado justamente en la actividad de mercadeo en la plaza medieval europea (Weber, 1964). Por otro lado, seguimos una línea argumental de Stillerman (2006) y Stillerman $\&$ Salcedo (2012), quienes afirman que en Chile tanto la feria callejera como el centro comercial pueden promover la esfera pública, dependiendo de situaciones específicas de apropiación de sus usuarios (discusión más detallada en Schlack et al., 2017).

En los tres casos analizados pudimos ver patrones diferenciados de accesibilidad local y metropolitana, así como diferentes tipos de comercio programados en los recintos comerciales y conformaciones de comunidades de comerciantes. Cada espacio de intercambio logra atraer la presencia de un público diverso y logra la interacción entre grupos diversos, de acuerdo a diferentes cualidades de accesibilidad y usos de suelo.
En relación al estudio del centro comercial, en esta investigación hemos dado evidencias de lo que ha descrito Wehrheim para casos en Alemania, donde la accesibilidad a grupos sociales diversos y la actividad que atrae a esta diversidad de usuarios condicionan el espacio con un carácter muy público (Wehrheim, 2007). También complementamos los hallazgos de investigaciones de Stillerman y Salcedo, quienes postulan que espacios de intercambio comercial, donde son posibles interacciones entre personas pertenecientes a grupos sociales diversos, donde existen procesos de apropiación y resistencia informal a las reglas impuestas por el dueño del lugar, se sitúan en barrios con mixtura social y con acceso desde el transporte público (Stillerman \& Salcedo, 2012). Específicamente, hemos comprobado que de los tres casos estudiados, el centro comercial es el que presenta un grupo socio-cultural más heterogéneo. Aunque el centro comercial se sitúa en un barrio de constitución mixta, el resultado de la investigación muestra que los usuarios de ese centro comercial no provienen del barrio circundante, sino que provienen en su mayoría de lugares distantes de la ciudad y que su accesibilidad es posible a través del metro. Este resultado nos permite entender que en la relación entre el comercio y su público, a veces es más determinante la accesibilidad metropolitana, dada en este caso por el metro, que en la constitución social de su entorno cercano. En este caso pudimos constatar que la relación de los habitantes del 
barrio circundante con el centro comercial es escaso y que se produce una gran diferencia entre la intensa relación que establece el centro comercial con barrios lejanos y el escaso vínculo que establece con los barrios circundantes.

Del estudio del mercado La Vega también surge un hallazgo sobre la relación con el entorno. Aquí habíamos esperado encontrar un grado de heterogeneidad social mayor que en las demás tipologías, ya que el mercado presenta, a primera vista, un paisaje socio-cultural variopinto. Sin embargo, pudimos verificar que la presencia de compradores de nivel socio-cultural más bajo era igual o menor que en las otras tipologías. En un análisis más detallado, descubrimos que la condición socialmente mixta del mercado se debe a presencia de compradores y de vendedores, y no solo de compradores. Los vendedores incluyen a trabajadores migrantes y a personas en situación de calle. La particular condición urbana del entorno del mercado ha permitido que estos grupos vivan cerca y trabajen en la Vega, contribuyendo así a construir una esfera pública, que de otra manera no sería posible. En este caso, el hallazgo se refiere a la importancia de la cercanía habitacional de grupos diversos del lugar y las posibilidades de accesibilidad desde lugares lejanos y cercanos al lugar para construir una diversidad socio-cultural.

La investigación también distinguió las diferentes motivaciones del público para acudir a cada una de las tres tipologías de comercio estudiadas. Las galerías atraen al público, porque están al paso y se funden con el comercio del entorno, el centro comercial se destaca por su oferta de entretención, confort y seguridad, que es mucho más escasa en el entorno. El mercado es atractivo por sus productos frescos y económicos, además del valor simbólico de su cultura de venta y regateo que genera una sensación de vitalidad propia del espacio público. Entendiendo que estas motivaciones se desprenden de determinadas formas de administración y de actores sociales que la componen, sostenemos que la heterogeneidad de los locatarios, así como la decisión sobre los tipos de rubros presentes en el lugar, inciden en la diversidad del público presente.

Los hallazgos de la investigación aportan información para imaginarnos la esfera pública resultante de una u otra combinación de tipos de comercio en un determinado barrio. Sabiendo que el fenómeno del comercio no se puede entender sin entender su contexto urbano (habitacional y accesibilidad), los resultados nos dan cuenta de las implicancias de ciertas tipologías comerciales en su entorno y respecto de la movilidad. Esto puede ser aplicado a criterios para definir prioridades de un tipo sobre otro de acuerdo al barrio donde se emplazan o criterios para discutir si debiese haber un equilibrio entre las diferentes formas de comercio. Todo esto nos indica que en nuestro campo del desarrollo 
urbano será necesario entender con cada vez mayor precisión, quiénes son y de dónde vienen los compradores y los trabajadores asociados a las diferentes tipologías de comercio. Así podremos diseñar formas de proteger la diversidad de usuarios y por tanto influir mediante decisiones de diseño urbano hacia la construcción de la esfera pública de los espacios urbanos.

\section{Bibliografía}

Arce, M.J. (2015). Aprendiendo de la Vega. Vitalidad como detonante proyectual. (Tesis Magister en Proyecto Urbano, sin publicar). Pontificia Universidad Católica de Chile, Santiago.

Bahrdt, H.P. 1979. La moderna metrópoli. Reflexiones sociológicas sobre la construcción en las ciudades. Buenos Aires: Ediciones de la Universidad de Buenos Aires.

Bannen, P. y Chateau, F. (Eds.) (2007). La ciudad de Providencia en la obra de Germán Bannen. Santiago de Chile: Ediciones ARQ.

Bastías, C., Hayden, C., e Ibáñez, D. (2011). Mujeres de la Vega: género, memoria y trabajo en la Vega Central de Santiago. Santiago de Chile: Consejo Nacional de la Cultura y las Artes.

Berding, U., Havemann, A., Pegels, J., \& Perenthaler, B. (2010). Stadträume in Spannungsfeldern. Plätze, Parks und Promenaden im Schnittbereich öffentlicher und privater Aktivitäten. Detmold: Rohn.
Carmona, M. (2015). London's local high streets: The problems, potential and complexities of mixed street corridors. Progress in Planning, 100, 1-84. https://doi.org/10.1016/j.progress.2014.03.001

Carmona, M., Magalhaes, C.d., \& Hammond, L. (2004). The smaller towns report. Delivering retail-led renaissance in towns and smaller cities. London: BCSC.

Castillo, S. (2014). El río Mapocho y sus riberas: espacio público e intervención urbana en Santiago de Chile (1885-1918). Santiago: Ediciones Universidad Alberto Hurtado.

Crawford, M. (1992). The world in a shopping mall. En M. Sorkin (Ed.), Variations on a theme park: The new American city and the end of public space (pp. 3-30). New York: Hill and Wang.

Delgadillo, V. (2017). Markets of La Merced: New frontiers of gentrification in the historic centre of Mexico City. En S. González (Ed.), Contested cities. Contested markets (pp. 17-35). London: Routledge.

Duhauy, E. y Giglia, A. (2007). Globalización e informalidad en la Ciudad de México. Prácticas de consumo y movilidad. Trace Travaux et recherches dans les Amériques du Centre, (51), 1-20. Recuperado de: http://journals.openedition.org/trace/632.

Erkip, F., Kizilgun, 0., \& Akinci, G.M. (2014). Retailer's resilience strategies and their impacts on urban spaces in Turkey. Cities, 36, 112-120. https://doi. org/10.1016/j.cities.2012.12.003

Fariña, C. (2015). Tipologías comerciales e infraestructuras de transporte. Coexistencias en torno al paradero 14 
de La Florida. (Tesis Magister, sin publicar). Pontificia Universidad Católica de Chile, Santiago.

Frieden, B. \& Sagalyn, L. (1989). Downtown, Inc.: How America rebuilds cities. Cambridge: MIT Press.

González, S. \& Waley, P. (2012). Traditional retail markets: The new gentrification frontier? Antipode, 45(4), 1-19. https://doi. org/10.1111/j.1467-8330.2012.01040.x.

Hermosilla, C. (2016). Nuevas formas y valores del manzanero central: La red de galerías comerciales de Santiago de Chile, estado y balance actual. (Tesis de Doctorado en Arquitectura, sin publicar). Pontificia Universidad Católica de Chile, Santiago.

Hidalgo, R. (2011). Las estaciones que fundaron el metro en Santiago de Chile. (Tesis de Doctorado en Arquitectura, sin publicar). Universidad Politécnica de Cataluña, Barcelona.

Ilustre Municipalidad de Santiago. (2006). Santiago centro un siglo de transformaciones. Santiago: autor.

Janssens, F. \& Sezer, C. (2013). Market places as an urban development strategy. Built Environment, 39(2), 169-171. https://doi.org/10.2148/benv.39.2.169.

Kayden, J., The New York City Department of City Planning \& The Municipal Art Society of New York. (2000). Privately owned public space: The New York city experience. New York: John Wiley.

Kozak, D. (2012). Construcción y transformaciones del Abasto, 1889-1998. Anales del IAA, 41(2), 213230. Recuperado de: http://www.iaa.fadu.uba.ar/ ojs/index.php/anales/article/view/62.
Lofland, L. (1998). The public realm: Exploring the city's quintessential social territory. Nueva York: Aldine de Gruyter.

Márquez, F. (2014). Inmigrantes en territorios de frontera. La ciudad de los otros. Eure, 40(120), 49-72. https:// doi.org/10.4067/S0250-71612014000200003.

Montes, C. (1989). La Florida puede más: hacia el centenario de la comuna (1899-1999). Santiago de Chile: Cordillera, Centro de Estudios Municipales.

Mora, R. y Herrmann, G. (2016). Flujos peatonales y vitalidad urbana: el caso de las galerías comerciales del centro de Santiago. En R. Mora y M. Vizcaíno, (Eds.), Interiores urbanos: comercio atraviesos e imaginario en las galerías del centro de Santiago, (pp. 57-78). Santiago: Ril.

Pérez, M., Salcedo, R. y Cáceres, G. (2012). Apropiación y control social de un centro comercial en Santiago: prácticas socioespaciales y significaciones adolescentes. Eure, 38(113), 53-75. https:// doi. org/10.4067/S0250-71612012000100003.

Reyes, S., Pavez, C., Penas, M., Salinas, F. y Hernández, A. (s.f.) Una década de cambios en las áreas verdes urbanas del Área Metropolitana de Santiago, Chile (2006-2016). En preparación.

Rosas, J. (1986). Manzana y tipo edificatorio en transformación. (Tesis de Doctorado, sin publicar). Escuela Técnica Superior de Arquitectura de Barcelona, Barcelona.

Rosas, J. (2006). Conformación y consolidación del centro de Santiago 1930-1960. En: Santiago centro. 
Un siglo de transformaciones, (pp. 40-53). Santiago: Ilustre Municipalidad de Santiago.

Sachs, W. (2002). Qualitative Stadt- und Gemeindeforschung. En U. Flick, Qualitative Sozialforschung. Reinbeck: Rowohlt.

Salazar, G. (2003). Ferias libres: espacio residual de la soberanía ciudadana. Santiago de Chile: Ediciones Sur.

Sato, A. (1981). Un simulacro urbano. Revista Punto, (63), 24-35.

Schlack, E. (2015). El espacio público en la nueva Providencia de Germán Bannen. En E. Schlack (Ed.), POPS-El uso público del espacio urbano (pp. 3-37). Santiago de Chile: Ediciones ARQ, UNAB, Capital Books.

(2011). Producción privada de espacio público. Espacios privados de uso público y la planificación por incentivos. Revista De Arquitectura, (24), 18-25. https://doi. org/10.5354/0719-5427.2013.26909

Schlack, E., Hidalgo, R., Arce, M.J., Fariña, C., y Villarroel, K. (2017). Espacios de intercambio comercial en Santiago de Chile: tres maneras de aportar a la esfera pública de áreas urbanas. Revista de Estudios Sociales, (60), 87-105. https://doi.org/10.7440/ res60.2017.07.

Schlack, E, Turnbull, N y Arce, M.J. 2017. Learning from La Vega Central: Challenges to the survival of a publicly used (private) marketplace. En S. González (Ed.), Contested Cities. Contested Markets (pp. 36-53). London: Routledge.
Selle, K. (2003). Was ist los mit den öffentlichen Räumen. Aachen: Dortmunder Vertrieb für Bau- und Planungsliteratur.

Siebel, W. (2007). Vom Wandel des öffentlichen Raumes. En J. Wehrheim (Ed.), Shopping Malls. Interdisziplinäre Betrachtungen eines neuen Raumtyps (pp. 77-94). Wiesbaden: VS Verlag.

Simone, L.d. (2017). The Latin American shopping centre: cultural translation, symbolic adaptation, and typological evolution of commercial architecture in Latin American cities. En J. Gosseye, T. Avermaete \& B. de Meulder (Eds.), Acculturating the shopping centre. London: Routledge.

(2015). Metamall. Santiago: Ril Editores.

Smithsimon, G. (2008). Dispersing the crowd: bonus plazas and the creation of public space. Urban Affairs Review, 43(3), 25-351. https://doi. org/10.1177/1078087407306325.

Sorkin, M. (1992). Variations on a theme park: The new American city and the end of public space. New York: Hill and Wang.

Stillerman, J. (2006). Private, parochial, and public realms in Santiago, Chile's retail sector. City \& Community, 5(3), 293-317. https://doi. org/10.1111/j.1540-6040.2006.00182.x.

Stillerman, J. \& Salcedo, R. (2012). Transposing the urban to the mall: Routes, relationships and resistance in two Santiago, Chile shopping centers. Journal of Contemporary Ethnography, 41(3), 309336. https://doi.org/10.1177/0891241611434551. 
Ünlü-Yücesoy, E. (2013). Constructing the marketplace: A socio-spacial analysis of past marketplaces in Istanbul. Built Environment, 39(2),190-202. https:// doi.org/10.2148/benv.39.2.190.

Vecslir, L. y Ciccolella, P. (2011). Relocalización de las actividades terciarias y cambios en la centralidad en la Región Metropolitana de Buenos Aires. Revista de Geografía Norte Grande, (49), 63-78. http:// dx.doi.org/10.4067/S0718-34022011000200005.

Villarroel, K. (2014). Comercio y espacio público. Atributos de vitalidad en torno al mall. (Tesis de Magister, sin publicar). Pontificia Universidad Católica de Chile, Santiago.

Von Hagen, J. (2015). El desafío de los espacios públicos de propiedad privada. La cambiante historia de la zonificación por incentivo en Nueva York. En E. Schlack (Ed.), POPS-El uso público del espacio urbano (pp. 111-133). Santiago de Chile: Ediciones ARQ, UNAB, Capital Books.

Whyte, W. 1980. The social life of small urban spaces. Washington, DC: The Conservation Foundation.

Weber, M. (1964). Economía y sociedad. México: Fondo de Cultura Económica.

Wehrheim, J. (2015). El carácter público de los espacios y de la ciudad. Indicadores y reflexiones para el posterior desarrollo del tema. En E. Schlack (Ed.), POPS-El uso público del espacio urbano (pp. 283305). Santiago de Chile: Ediciones ARQ, UNAB, Capital Books.

(2009). Der Fremde und die Ordnung der Räume. Opladen: Barbara Budrich.
(2007). Shopping Malls. Interdisziplinäre Betrachtungen eines neuen Raumtyps. Wiesbaden: VS Verlag.

Zukin, S. (1995). The cultures of cities. Cambridge: Blackwell.

(1990). Socio-spatial prototypes of a new organization of consumption: The role of real cultural capital. Sociology, 24(1), 37-56. https://doi.or g/10.1177/0038038590024001005. 